
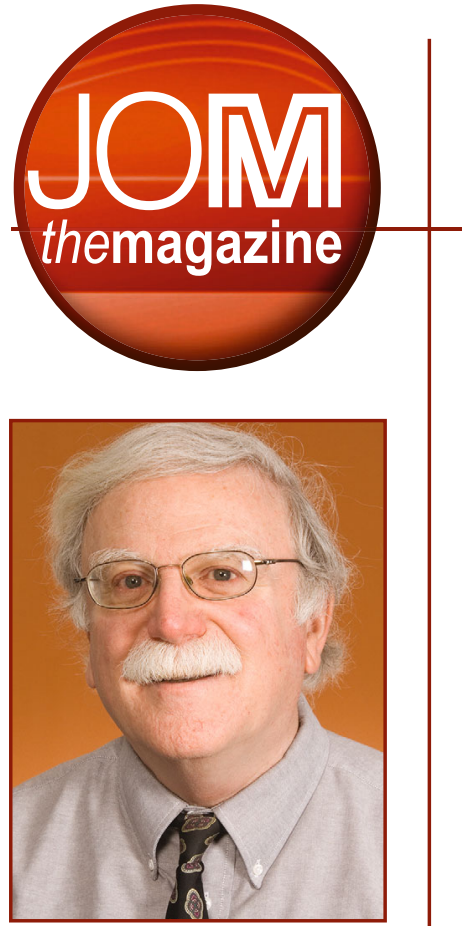

David E. Laughlin
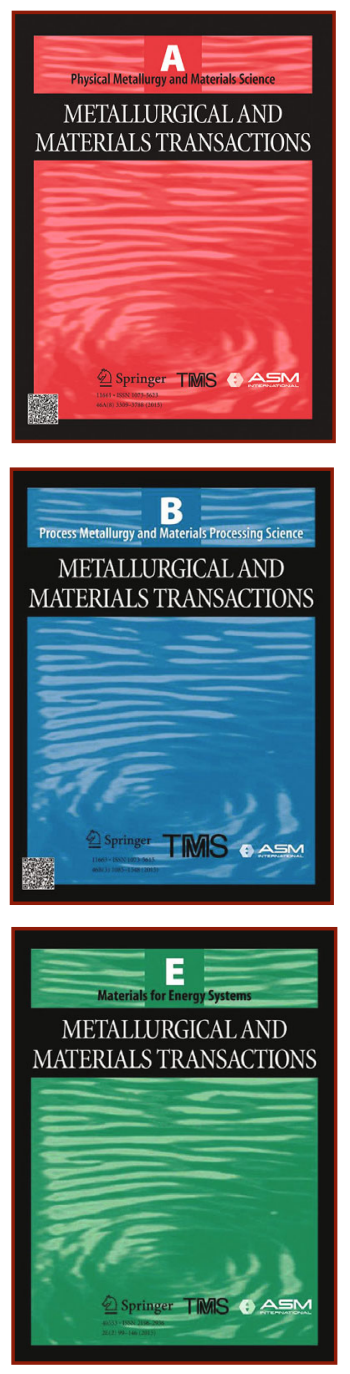

\title{
David Laughlin Leaves a Legacy of Excellence
}

\section{Lynne Robinson}

\section{TMS content update}

Look for news and updates on TMS publications and online resources, as well as opportunities for editors and authors, in this regular JOM feature.

David E. Laughlin has been part of Metallurgical and Materials Transactions (Met Trans) from the earliest days of its history.

Established in 1969 as Metallurgical Transactions, the publication merged the content of Transactions of the Metallurgical Society of AIME (now TMS) and the ASM Transactions Quarterly into a journal "providing coverage of all significant areas of metallurgical research," as noted in a joint leadership letter to members of both societies. Laughlin published his second ever paper in 1974 in Met Trans. He started reviewing papers for Met Trans that same year, as a first-year assistant professor at Carnegie Mellon University. Within two years, he was appointed to the Met Trans Board of Review as a key reader, and in 1982, was named an associate editor. He was appointed to the position of editor in 1987. "I was happy to do this as it was an opportunity to continue to serve the materials community in an important role," he said.

As Laughlin's role evolved, so did Met Trans. To better meet the specific needs and interests of its readers, Met Trans rolled out two distinct publications in 1975. Met Trans A, a monthly journal, focused on the latest research in all aspects of physical metallurgy and materials science. The bi-monthly Met Trans B offered a forum for the exploration of process metallurgy and materials processing science. What did not change was the inter-society cooperation embodied by the Met Trans Joint Commission, representing both TMS and ASM members, that helps to guide the editorial direction and strategic development of the journals to this day.

Met Trans has grown exponentially in readership and prestige with Laughlin at the helm, shaped by his editorial vision and leadership to a team of volunteers that numbers in the hundreds. (His title was eventually changed from editor to principal editor to reflect the scale of these efforts.) In 1994, Met Trans changed its name to Metallurgical and Materials Transactions to encompass the breadth of materials science and engineering. In 2014, it added a third journal to its ranks, Metallurgical and Materials Transactions E: Materials for Energy Systems.

Now the Alcoa Professor of Physical Metallurgy at Carnegie Mellon University, Laughlin will step down from his Met Trans editorship at the end of 2016. To ensure a smooth transition, he will work with the incoming principal editor, Tresa M. Pollock, Alcoa Professor and chair, Department of Materials, University of California, Santa Barbara, once she begins her editorship on September 1.

Looking back over his many years of distinguished service, Laughlin noted, "In particular, I am proud of the rigorous review process and the high quality micrographs that are published in our journals. Of great importance is that we do not reject papers out of hand because they are not currently hot topics. Our judgment is based on the quality of the work, not on how recent the topic. Our papers are well cited many years after their publication."

Laughlin is quick to point out, though, that shepherding the growth and development of Met Trans has been far from a solitary journey. "I have been extremely fortunate to have had a dedicated team of editors who have been diligent in their jobs, making mine a little easier," he said. "Many of the key readers are also extremely dedicated to the journal, as are many of the reviewers. Needless to say, without all of them, our work would have been in vain." 